\title{
$17^{\circ}$ ERGODESIGN \& USIHC 2019 \\ PUC-Rio, 11 a 13 de dezembro Rio de Janeiro, RJ, Brasil
}

\section{Apoiador de Muletas}

\author{
Mulet Supporter
}

\author{
SILVA, Leopoldo Engroff \\ Universidade Federal de Santa Maria - UFSM, Acad. \\ lengroffs@hotmail.com \\ BRONDANI, Sergio Antônio \\ Universidade Federal de Santa Maria - UFSM, Dr. \\ serbrondani@gmail.com
}

\section{RESUMO}

Tecnologia Assistiva também significa projetar produtos/equipamentos para auxiliar no cotidiano das pessoas, promovendo maior conforto, assistência e segurança. Assim sendo, esta pesquisa tem como principal objetivo o desenvolvimento de um novo projeto de produto que favoreça a sustentação e acomodação de muletas e bengalas, quando o usuário não estiver as utilizando. São evidenciados os aspectos ergonômicos e do design universal, promovendo formas e dispositivos que facilitem seu uso e manuseio. De acordo com a análise sincrônica efetuada, a proposta desenvolvida é diferenciada se comparada com os similares disponíveis no mercado brasileiro. A revisão bibliográfica atenta para além das questões de usabilidade, pois foca em uma metodologia para análise de uso com avaliação real do experimento. Com base em entrevistas e observações das atividades cotidianas do usuário, foram extraídos os elementos que proporcionaram importantes ajustes e adequações. Assim, obtivemos os requisitos básicos para o desenho do novo produto, bem como a sua materialização e posterior análise de uso. Como resultado deste processo, foi apresentado um novo produto, cujo modelo foi construído em madeira e com acabamento em pintura acrílica. Embora o desenvolvimento da pesquisa envolveu a abordagem de um usuário, na análise do uso ficou demonstrada a condição favorável para uma grande maioria dos que utilizam muletas. Resume-se em um produto que apresenta uma condição segura e de fácil manuseio.

Palavras-chave: design universal; ergonomia; muleta; tecnologia assistiva; usabilidade.

\section{ABSTRACT}

Assistive technology also means designing products / equipment to assist in people's daily lives, promoting greater comfort, assistance and safety. Therefore, this research has as main objective the development of a new product project that favors the support and accommodation of crutches and canes, when the user is not using them. The ergonomic and universal design aspects are highlighted, promoting shapes and devices that facilitate its use and handling. According to the synchronous analysis performed, the proposal developed is differentiated compared to similar ones available in the Brazilian market. The literature review looks beyond usability issues, as it focuses on a methodology for use analysis with real evaluation of the experiment. Based on interviews and observations of the user's daily activities, the elements that provided important adjustments and adjustments were extracted. Thus, we obtained the basic requirements for the design of the new product, as well a its materialization and subsequent use analysis. As a result of this process, a new product was presented, whose model was built in wood and finished in acrylic paint. Although the development of the research involved the approach of one user, the use analysis showed the favorable condition for a large majority of those using crutches. It comes down to a product that is safe and easy to handle.

Keywords: universal design; ergonomics; crutch; assistive technology; usability. 


\section{$17^{\circ}$ ERGODESIGN \& USIHC 2019 \\ PUC-Rio, 11 a 13 de dezembro Rio de Janeiro, RJ, Brasil}

\section{INTRODUÇÃO}

Pesquisadores de diferentes áreas de atuação consideram o Desenho Industrial, como fundamental para a materialização de formas e funcionamento de dispositivos que possam auxiliar no desenvolvimento de novos produtos do nosso cotidiano. Não existe mágica nem somente intuição, mas muito conhecimento e perseverança.

Junta-se a esse conhecimento, pessoas com diferentes saberes e com vontade de vencer grandes desafios. Propor novas soluções requer uma cuidadosa avaliação, definindo metas para então atingir os objetivos propostos. Baxter (2011) contextualiza em seu livro a importância e o significado que um novo produto deve apresentar como opção favorável para a sua aquisição.

Muitas vezes, o consumidor não tem oportunidade de verificar o seu funcionamento efetivo, antes de realizar a compra. Grande parte do julgamento sobre seu funcionamento é feito, então, pela sua aparência visual. Os produtos devem transmitir a impressão de que executam bem o objetivo para o qual foram projetados. Essa área chama-se semântica do produto: literalmente, o significado do produto. (BAXTER, 2011, p. 79).

A contextualização apresentada serviu de base e delineamento para o desenvolvimento da pesquisa, propondo um novo projeto de equipamento que venha suprir a necessidade verificada. O desenvolvimento do projeto procurou atender as necessidades de um acadêmico, aluno do curso de Engenharia Acústica da Universidade Federal de Santa Maria/RS. O pedido para esta demanda ocorreu junto ao Núcleo de Acessibilidade da instituição, responsável por atender e solucionar as necessidades dos acadêmicos ingressantes e que necessitam de algum auxílio para a sua condição física, cognitiva ou sensorial. O uso permanente de muletas para a sua locomoção diária é resultado das patologias de um diagnóstico de esclerose múltipla.

Os produtos existentes no mercado e que possuem as mesmas funções, isto é, apoio para muletas, apresentam muitas restrições nas possibilidades de uso. Assim sendo, esta pesquisa tem como principal objetivo, projetar um novo equipamento que favoreça à uma ampla possibilidade de suporte de fixação de suas muletas em diferentes bases de apoio. A justificativa maior na busca por auxílio se deu pelo constrangimento diário do acadêmico em sala de aula. Os locais onde possibilita depositar sua muleta, compromete não só os seus movimentos na mesa, mas também o fluxo de deslocamentos dos demais colegas em sala.

\section{REVISÃo BIBLIOGRÁFICA}

As temáticas referentes à doença - Esclerose Múltipla, à inclusão e à ergonomia, farão parte do conteúdo apresentado para compreensão dos resultados obtidos com o desenvolvimento desta pesquisa.

\subsection{Esclerose Múltipla}

A Esclerose Múltipla (EM) é uma doença autoimune que afeta o cérebro, nervos ópticos e a medula espinhal (Sistema Nervoso Central - SNC). Isso acontece porque o sistema imunológico do corpo confunde células saudáveis com "intrusas", e as ataca provocando lesões.

Os sintomas variam amplamente, dependendo da quantidade de danos e os nervos que são afetados. Caracteriza-se por ser uma doença potencialmente debilitante. A EM atinge cerca de 2,5 milhões de pessoas no mundo. A doença não tem cura, mas os tratamentos podem ajudar a controlar os sintomas e reduzir a progressão da doença. Suas causas exatas não 


\section{$17^{\circ}$ ERGODESIGN \& USIHC 2019 \\ PUC-Rio, 11 a 13 de dezembro Rio de Janeiro, RJ, Brasil}

são conhecidas, mas pesquisas sugerem que podem ser de ordem genética, como também em função do ambiente em que a pessoa vive ou até mesmo um vírus. Sendo um tema muito pesquisado atualmente, favorece uma constante e significativa evolução na qualidade de vida dos pacientes.

Pessoas com EM tendem a apresentar os primeiros sintomas na faixa dos 20 a 40 anos. Alguns podem ir e vir, enquanto outros permanecem. Também se diferenciam entre pessoas, pois, dependem dos nervos que são afetados. De maneira geral, os primeiros sintomas são dores crônicas, perda de força, fadiga, comprometimento da visão, entre outros. Percebe-se facilmente quanto é mais complicado para uma pessoa com EM exercer suas atividades do que para uma pessoa saudável, portanto, faz-se necessário a adaptação ao uso de equipamentos. Essas adaptações são no sentido de melhor adequação das habilidades, limitações e das funções que desempenha.

\subsection{Inclusão}

Descrever sobre inclusão, nos remete a esclarecer temas como Acessibilidade e Design Inclusivo. Conforme relatos, são conceitos diferentes, mas que com ambos o indivíduo tem a capacidade de projetar a própria vida, de entrar em relação com os outros e como conseqüência, participar da construção da sociedade. "Ủm se destina exclusivamente à busca de soluções com adaptações em ambientes, em produtos ou em serviços para atender às diferenças funcionais, já o outro busca soluções onde o olhar para diversidade seja a essência do projeto" (GOMES e QUARESMA, 2018, p.20).

A todas as formas que de alguma maneira agregam positivamente nas pessoas, podemos afirmar que propiciam autonomia e favorecem a obter resultados e conquistas positivas.

Para a Associação Brasileira de Normas Técnica - ABNT - NBR 9050, a acessibilidade é apresentada com a seguinte definição: possibilidade e condição de alcance, percepção e entendimento para a utilização com segurança e autonomia de edificações, espaço, mobiliário, equipamento urbano, e elementos.

Colabora para o atendimento às condições adversas apresentadas na tipologia humana, medidas, princípios e recomendações que possam de alguma maneira atender a necessidade do cotidiano. Neste sentido, apresentamos os Princípios do Design Universal, bem como as categorias dos recursos e serviços da Tecnologia Assistiva, meios pelos quais possam auxiliar na solução dos problemas. Os itens grifados foram os que mais se destacaram na proposta apresentada como conceito do novo equipamento.

\subsubsection{Princípios do Design Universal}

Elaborado por designers, arquitetos, engenheiros, terapeutas ocupacionais e coordenados pelo Centro de Design Universal da Universidade da Carolina do Norte - EUA.

1. Equiparação das possibilidades de uso;

2. Flexibilidade no uso; (facilitar a acuidade e a precisão do usuário).

3. Uso simples e intuitivo; (acomodar a ampla gama de capacidades de leitura e habilidades lingüísticas do usuário).

4. Informações perceptíveis; (disponibilizar contrastes adequados).

5. Tolerância ao erro;

6. Mínimo esforço físico;

7. Dimensionamento de espaços para acesso e uso de todos os usuários. 


\section{$17^{\circ}$ ERGODESIGN \& USIHC 2019 \\ PUC-Rio, 11 a 13 de dezembro Rio de Janeiro, RJ, Brasil}

\author{
$17^{\circ}$ Ergodesign - Congresso Internacional de Ergonomia e \\ Usabilidade \\ de Interfaces Humano Tecnológica: Produto, Informações Ambientes \\ Construídos e Transporte \\ $17^{\circ}$ USIHC - Congresso Internacional de Ergonomia e Usabilidade \\ de Interfaces Humano Computador
}

\subsubsection{Tecnologias Assistivas}

Iniciando a revisão bibliográfica, utilizamos a definição de (BERSCH e TONOLLI, 2006) em que afirmam que a Tecnologia Assistiva ainda é considerada uma área nova, usada para identificar todos os recursos e serviços que proporcionam e ampliam as habilidades funcionais de pessoas com deficiência e assim, conseqüentemente, promover vida, independência e inclusão.

Segundo o Comitê Brasileiro de Ajudas Técnicas (BRASIL - SDHPR, ATA VII), a Tecnologia Assistiva é uma área do conhecimento, de característica interdisciplinar, que engloba produtos, recursos, metodologias, estratégias, práticas e serviços que objetivam promover a funcionalidade, relacionada à atividade e participação, de pessoas com deficiência, incapacidades ou mobilidade reduzida, visando sua autonomia, independência, qualidade de vida e inclusão social.

São recursos e serviços que contribuem para proporcionar ou ampliar habilidades funcionais. Se compõem de 12 categorias:

1. Auxílios para a vida diária;

2. Comunicação aumentativa (suplementar) e alternativa;

3. Recursos de acessibilidade ao computador;

4. Sistemas de controle de ambientes;

5. Projetos arquitetônicos para acessibilidade;

6. Órteses e Próteses;

7. Adequação postural;

8. Auxílios de mobilidade;

9. Auxílios para cegos ou com visão subnormal;

10. Auxílio para surdos ou com déficit auditivo;

11. Adaptações em veículos.

12. Esporte e Lazer.

\subsection{Ergonomia}

Diante das três áreas de especialização da ergonomia, definidas como ergonomia física, ergonomia cognitiva e ergonomia organizacional, nossa pesquisa buscou os referenciais no que tange às condições físicas. Segundo Abrahão (2009), esta área da ergonomia refere-se a anatomia humana, antropometria, fisiologia e biomecânica. É avaliada a postura no trabalho, manuseio de materiais, movimentos repetitivos, projeto de posto de trabalho, segurança e saúde.

A característica do equipamento projetado exige um cuidado especial no que se refere ao manejo por parte do usuário. Assim, podemos utilizar os conceitos adotados por lida (2005), que define manejo como uma forma particular de controle, em que no processo da pega há um predomínio dos dedos e da palma das mãos, prendendo ou manipulando alguma coisa. A mão humana é uma das "ferramentas" mais completas, versáteis e sensíveis que se conhece. Graças a grande mobilidade dos dedos, e o dedo polegar trabalhando em oposição aos demais, pode-se conseguir uma grande variedade de manejos, com variações de força, precisão e velocidade dos movimentos. Em cada tipo de manejo pode haver predominância de alguns desses aspectos. Cortar arame com alicate exige força, montar pequenas peças exige precisão e tricotar exige velocidade. (IIDA, 2005, p.243).

De maneira geral podemos definir dois tipos básicos de manejos: fino e grosseiro. O manejo fino é executado com a ponta dos dedos e o manejo grosseiro ou de força, é executado com o centro da mão. Esta condição é a que se enquadra o produto desenvolvido, considerando que os dedos fiquem relativamente estáticos prendendo na empunhadura. $\mathrm{A}$ 


\section{$17^{\circ}$ ERGODESIGN \& USIHC 2019 \\ PUC-Rio, 11 a 13 de dezembro Rio de Janeiro, RJ, Brasil}

força dos movimentos para o caso pesquisado caracteriza-se como uma pega grosseira do tipo empunhadura, podendo a força chegar a $40 \mathrm{Kg}$.

Segundo o autor, ao se projetar novos equipamentos, devem ser consideradas as formas diferentes de pega. Basicamente podem ser classificadas em dois tipos: geométrica e antropomorfa. Como o próprio nome diz, a geométrica se assemelha a uma figura geométrica qualquer enquanto que a antropomorfa (forma utilizada no desenvolvimento do apoiador de muletas) apresenta um desenho com superfície arredondada, conformando-se com a anatomia da parte da mão usada no manejo.

\subsection{Características desejáveis do equipamento:}

Referente aos aspectos cognitivos, Baxter (2011) afirma que todos os produtos procuram satisfazer as necessidades humanas e assim, direta ou indiretamente, entram em contato com o homem. Para uma boa aceitação nessa relação é importante observar algumas características:

- Qualidade técnica: é a parte do funcionamento do equipamento sob o ponto de vista mecânico. É considerada a eficiência na execução das funções bem como a facilidade de limpeza e manutenção;

- Qualidade ergonômica: é a que garante a boa interação do equipamento com o usuário. Inclui a facilidade de manuseio, adaptação antropométrica, fornecimento claro das informações, compatibilidades de movimentos, facilidades de ajustes e leituras, demais itens de conforto e segurança;

- Qualidade estética: é a que proporciona prazer ao usuário. É resultado de uma combinação de formas, cores, materiais, texturas, acabamentos e movimentos.

Pela carência no mercado de produtos com esta função, o projeto então torna-se atraente e desejável. Segundo o autor, quando o consumidor deseja o produto, estará vencida mais da metade da batalha de marketing desse produto. Assim podemos definir sua atração semântica, que significa transmitir a impressão de confiança. A forma como é construído, informa desempenhar bem sua função.

\section{METODOLOGIA}

A pesquisa é fruto da demanda encaminhada junto ao Núcleo de Acessibilidade da UFSM e possui como propósito, a solução dos problemas. Este núcleo é composto por uma equipe multidisciplinar de designers, educadores especiais, terapeutas ocupacionais e fisioterapeutas.

Classificada como uma pesquisa descritiva, preocupa-se em descobrir e observar fenômenos, procurando descrevê-los, classificá-los e interpretá-los. Segundo afirmação de Moraes e Mont'Alvão (2000), a ergonomia, ao avaliar as condições de trabalho e analisar a tarefa, realiza pesquisas descritivas. A metodologia utilizada nestes casos compreende uma observação sistemática direta, em que são planejados os sentidos sobre os fenômenos. Para conhecer e compreender os procedimentos do usuário com o equipamento analisado (apoiador de muletas), foram realizadas algumas reuniões colocando em prática as ações rotineiras. No planejamento e controle das análises, foram propostas diferentes construções do equipamento para análises dos testes. A referida observação sistemática foi utilizada na etapa do diagnóstico, durante a análise da tarefa, nas posturas operacionais e manipulação com o equipamento. 


\title{
$17^{\circ}$ ERGODESIGN \& USIHC 2019 \\ PUC-Rio, 11 a 13 de dezembro Rio de Janeiro, RJ, Brasil
}

\author{
$17^{\circ}$ Ergodesign - Congresso Internacional de Ergonomia e \\ Usabilidade \\ de Interfaces Humano Tecnológica: Produto, Informações Ambientes \\ Construídos e Transporte \\ $17^{\circ}$ USIHC - Congresso Internacional de Ergonomia e Usabilidade \\ de Interfaces Humano Computador
}

\subsection{A situação de trabalho analisada:}

Para o desenvolvimento da pesquisa foram questionados quais são os diferentes elementos em interação com a atividade do homem, que são importantes para a análise no contexto da tarefa desenvolvida. Segundo Santos e Fialho (1995), esta é uma questão concreta de metodologia ergonômica, tendo em vista um resultado determinado esperado. Neste sentido, a atividade de trabalho é a maneira como esse resultado é obtido, isto é, a ação ou forma de manejar um instrumento.

\subsection{Levantamento de dados}

Utilizando a Análise Ergonômica do Trabalho (AET) como metodologia de pesquisa, foi então trabalhado um processo investigativo que se apresenta em três etapas:

- Na primeira etapa foram feitas as análises das referências bibliográficas sobre o indivíduo em suas ações, observando e registrando conforme seus relatos pessoais.

- A segunda etapa é constituída por três fases: análise da demanda, análise da tarefa e análise da atividade.

$\mathrm{Na}$ análise da demanda, o objetivo foi definir o problema a ser estudado, a partir de acordo prévio com os atores envolvidos (pesquisadores e acadêmicos). Foi a fase de coleta de dados, observando o fazer durante a atividade laboral, permitindo assim a formulação da hipótese: os problemas identificados durante as ações cotidianas serão facilmente solucionados com o uso de um equipamento que auxiliasse o apoio das muletas. Condições do usuário - acadêmico de graduação do curso de Engenharia Acústica da UFSM: idade $=27$ anos.

$\mathrm{Na}$ análise da tarefa, foram observadas as situações do cotidiano em que o usuário de muletas está exposto considerando o sistema homem/tarefa. Foram analisadas as diversas situações, inclusive as que causam constrangimentos posturais ao usuário.

$\mathrm{Na}$ análise da atividade, foram observadas as posturas, ações, gestos, movimentos, estratégias, modos operativos, enfim, tudo que se referiu a conduta do pesquisado. No desenvolvimento de suas atividades no cotidiano, o pesquisado apresenta dificuldades para encontrar locais adequados para apoiar às muletas próximo a ele, principalmente quando está em sala de aula. Esta condição, segundo seu relato, acontece em quase todos os lugares que freqüenta.

A terceira etapa, consiste na síntese ergonômica do trabalho e as devidas recomendações ergonômicas. É neste estágio que as conclusões são apresentadas, resultante das fases anteriores realizadas.

Segundo Abrahão (2009), quando nos reportamos à AET enquanto método, estamos nos referindo a um conjunto de etapas e ações que mantém uma coerência interna, principalmente quanto a possibilidade de se questionar os resultados obtidos durante a coleta de dados, validando-os ao longo do processo e aproximando-os mais da realidade pesquisada. Diferente dos métodos científicos tradicionais, em que as hipóteses são previamente elaboradas e explicitadas, na AET elas são construídas, validadas e/ou refutadas ao longo do processo.

As condições físicas para testes com os protótipos se deram em uma sala de reuniões, com aproximadamente $20 \mathrm{~m}^{2}$, localizada junto às dependências do Núcleo de Acessibilidade, equipada com mesas e cadeiras. As condições de conforto ambiental estavam dentro de parâmetros legais, ventiladas adequadamente e iluminadas de acordo com as 
recomendações normativas para leitura/sala de aula para pessoas em condições "normais" de visão - 300 lux (NBR 5413 - Níveis recomendados de lluminamento para interiores). Equipamentos utilizados para registros e medições:

- Câmara fotográfica digital, marca Nikon - modelo D 3300.

- Fita métrica para medidas das mãos.

- Testes com tipologias de molas de aço (04) para avaliação e adaptação da força por parte dos usuários testados. Por não ter o equipamento que é próprio para a leitura da força, optamos pela sensibilidade dos usuários com seus depoimentos em entrevistas após os testes realizados. Além do ator pesquisado, participaram desta fase de testes outros dois colaboradores e usuários de muletas, sendo um deles cego (idade 36) e o outro usuário de próteses nos membros inferiores (idade 23). Podemos afirmar que os três colaboradores estão com os membros superiores (braços e mãos) em plenas condições de uso, não necessitando de condições especiais para empunhadura na avaliação das forças. Para atender o desejo do usuário foi então desenvolvido um projeto de produto como sendo uma novidade utilitária. Neste sentido foi definido então materializar um produto de baixa complexidade, baixo investimento e simplicidade na fabricação e montagem. A proposta apresenta viabilidade técnica, pois é desenvolvida com materiais disponíveis no nosso mercado, com um processo produtivo conhecido (máquina CNC - Computer Numeric Control) e mão de obra já capacitada. Com estas condições se define a viabilidade econômica, pois não necessita de alto investimento e resulta em um produto de baixo custo. Definidos os requisitos de projeto e hierarquizadas as funções, foi então iniciado a exploração de idéias. A escolha da proposta foi definida com a avaliação principalmente do usuário, objeto da pesquisa, e dos colaboradores participantes já mencionados, considerando as condições e habilidades funcionais. Após a definição do conceito, foi iniciado o desenvolvimento para a configuração do projeto.

Figura 1. Fase de elaboração de ideias. Fonte: Acervo do pesquisador.

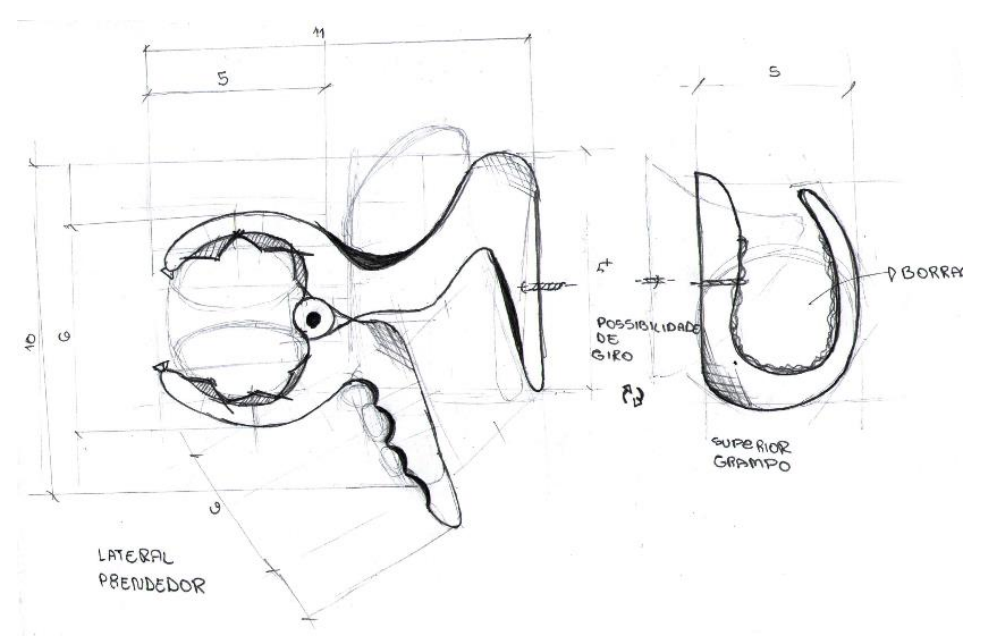

A geração de ideias são apresentadas inicialmente em forma de desenhos, que após as análises entre pesquisadores e pesquisado, foram materializadas em um mocape para submetê-lo às análises de pega e força. 


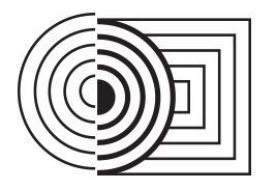

$17^{\circ}$ ERGODESIGN \& USIHC 2019

PUC-Rio, 11 a 13 de dezembro Rio de Janeiro, RJ, Brasil $17^{\circ}$ Ergodesign - Congresso Internacional de Ergonomia e Usabilidade

de Interfaces Humano Tecnológica: Produto, Informações Ambientes

Construídos e Transporte

$17^{\circ}$ USIHC - Congresso Internacional de Ergonomia e Usabilidade

de Interfaces Humano Computador

Figura 2. Construção de mocapes para análises de uso. Fonte: Acervo do pesquisador.

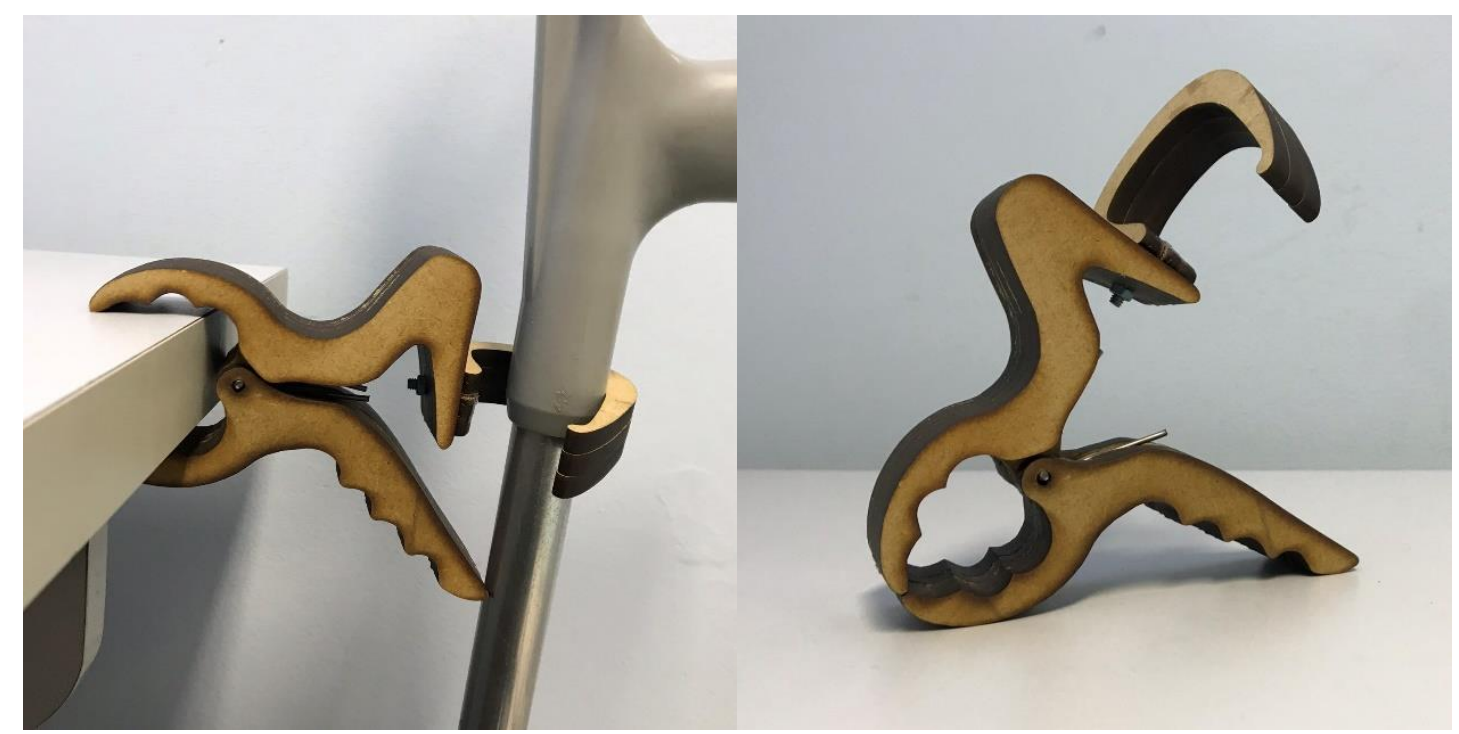

A etapa de análise e uso dos mocapes foi de fundamental importância, principalmente por dar sinal de continuidade e progressão da pesquisa. Foram definidos parâmetros a serem incorporados na definição e construção do modelo. Foi acrescentado como adequação para a proposta final, o aumento do tamanho da pega e do grampo de fixação. O envio para a produção se deu com a definição do projeto executivo, contendo detalhamentos e componentes de instalação.

\section{RESULTADOS}

Para favorecimento do encaixe da palma da mão e dos dedos, foi então projetado uma pega com saliências, definida como anatômica. Esta proposta de desenho antropomorfo apresenta maior superfície de contato, permite maior firmeza de pega, transmissão de maiores forças, com concentração menor de tensões em relação à pega geométrica. Por ser uma postura de posição com freqüência intermitente, de curta duração e não exigindo muitos movimentos relativos, não se torna fatigante o processo de manuseio para a fixação da peça.

No acabamento superficial da pega foi proposta uma superfície áspera e emborrachada para aumentar o atrito com as mãos, diluindo assim as tensões. Foram evitados cantos "vivos" ou rebarbas para não haver concentrações de pressões e assim provocar lesões nas mãos.

Decorrente do processo de desenvolvimento da pesquisa e buscando solucionar os problemas, é então apresentado o novo produto. Considerado como a terceira materialização (mocape), foi construído com cinco lâminas de madeira MDF (Medium Density Fiberboard) para a empunhadura e uma camada de três lâminas no grampo de fixação e apoio das muletas, espessura de $6 \mathrm{~mm}$, cortadas na máquina CNC, fixadas e prensadas com cola especial para madeira. Após o lixamento e preparação da base, foi dado o acabamento final com resina e tinta acrílica aplicadas sobre o fundo preparado. Especificamente na área da pega, foi fixada uma borracha tipo EVA (Etil, Vinil e Acetato) com espessura de $2,5 \mathrm{~mm}$, nas cores roxa e cinza fosco, para auxiliar na firmeza e segurança. 


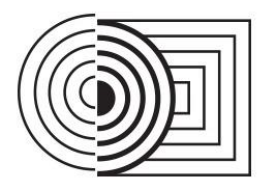

$17^{\circ}$ ERGODESIGN \& USIHC 2019

PUC-Rio, 11 a 13 de dezembro Rio de Janeiro, RJ, Brasil $17^{\circ}$ Ergodesign - Congresso Internacional de Ergonomia e Usabilidade

de Interfaces Humano Tecnológica: Produto, Informações Ambientes

Construídos e Transporte

$17^{\circ}$ USIHC - Congresso Internacional de Ergonomia e Usabilidade

de Interfaces Humano Computador

Figura 3. Modelo desenvolvido e avaliado.

Fonte: Acervo do pesquisador.

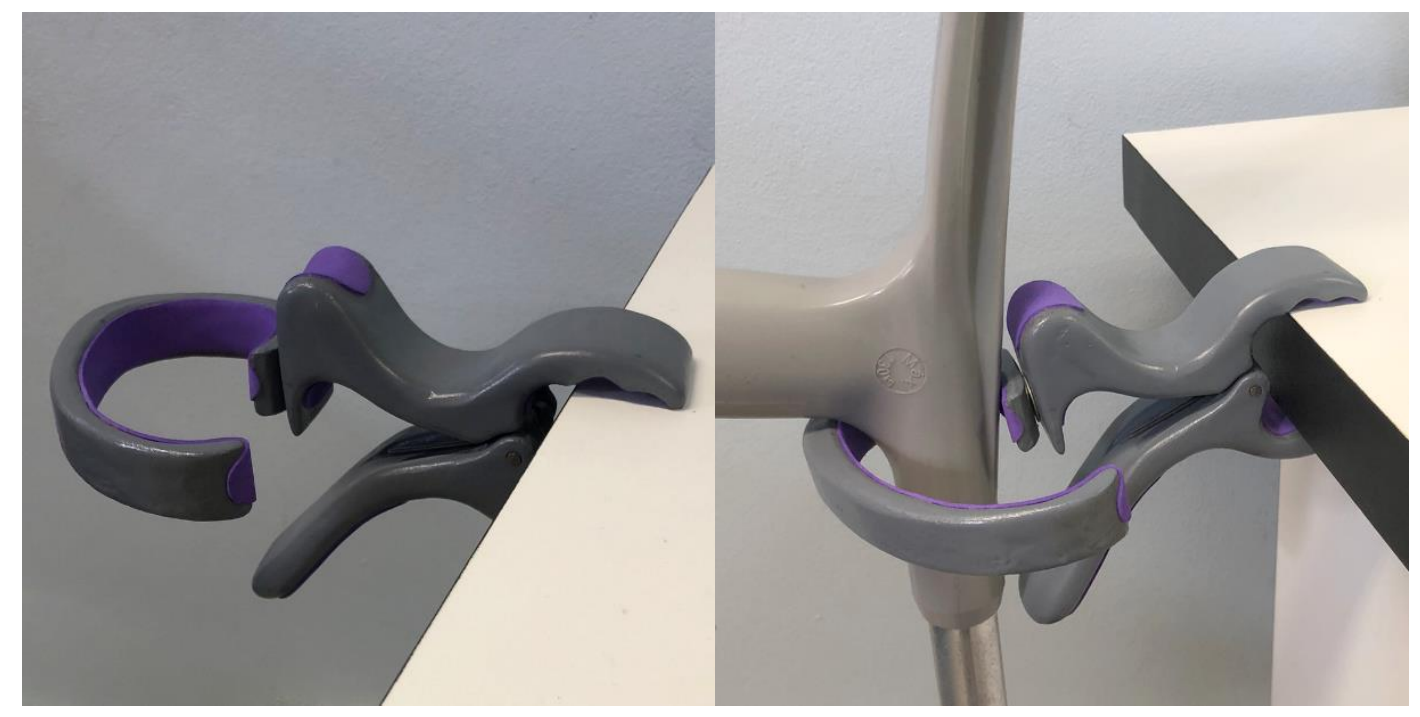

Para favorecimento do encaixe da palma da mão e dos dedos, foi então projetado uma pega com saliências, definida como anatômica. Esta proposta de desenho antropomorfo apresenta maior superfície de contato, permite maior firmeza de pega, transmissão de maiores forças, com concentração menor de tensões em relação à pega geométrica. Por ser uma postura de posição com freqüência intermitente, de curta duração e não exigindo muitos movimentos relativos, não se torna fatigante o processo de manuseio para a fixação da peça.

Os princípios do Design Universal e as categorias da Tecnologia Assistiva foram plenamente atendidas e serviram de parâmetros para nortear todo o desenvolvimento da pesquisa até a apresentação do seu resultado final. Foram de certa maneira utilizados como requisitos para hierarquizar as funções contempladas, considerando a diversidade das pessoas que analisam o uso no modelo final apresentado.

\section{CONCLUSÃO}

O caráter excepcional e motivador para um pesquisador que atua nas áreas de acessibilidade e usabilidade, é sem dúvidas, trabalhar com pesquisas aplicadas. Além da experiência acadêmica para estruturar, aplicar e redigir a pesquisa, também proporciona uma relação próxima de sentimentos e ações que muitas vezes se confundem com os aspectos afetivos dos envolvidos nas análises. É oportuno aqui relatar as palavras do próprio usuário de muletas que foi objeto da demanda inicial da pesquisa, em que afirma: "Nunca me senti tão acolhido". Só nestas palavras se resumem todo o sentimento de aprovação pelo que o método utilizado proporcionou. Também foi observada a gratidão pelo usuário cego, no que se refere a fácil adaptação ao uso. O desenvolvimento do projeto final atendeu aos objetivos da pesquisa de favorecer à uma ampla possibilidade de suporte de fixação de muletas em diferentes bases de apoio. A hipótese inicial que previa solucionar o problema apresentado com o uso do novo equipamento, foi confirmada durante o processo de desenvolvimento da pesquisa. A análise de uso com três pessoas não caracteriza nenhuma amostra estatística, mas com certeza fornece subsídios de uma metodologia possível para ser implantada e avaliada com padrões determinados. 
Além do compromisso assumido em atender uma demanda determinada, ficou na equipe de pesquisadores uma vontade ainda maior em prosseguir nos desafios que virão, tentando desta forma aglutinar e conscientizar mais pessoas da importância da nossa missão enquanto educadores. Vale muito apostar no ser humano.

\section{REFERÊNCIAS BIBLIOGRÁFICAS}

ASSOCIAÇÃO BRASILEIRA DE NORMAS TÉCNICAS. NBR 9050: Acessibilidade a edificações, mobiliário, espaços e equipamentos urbanos. Rio de Janeiro, 2014.

ABRAHÃO, Júlia; SZNELWAR, Laerte; SILVINO, Alexandre; et. al. Introdução à ergonomia: da prática à teoria. - São Paulo: Blücher, 2009.

BAXTER, Mike. Projeto de produto: guia prático para o design de novos produtos. 3.ed. São Paulo: Blucher, 2011.

BERSCH, Rita; TONOLLI, José. Introdução ao conceito de tecnologia assistiva. Porto Alegre: Disponível em: http://www.assistiva.com.br/ Acesso em: 14 set. 2019.

BRASIL. SDHPR - Secretaria Nacional de Promoção dos Direitos da Pessoa com Deficiência - SNPD. 2012 Disponível em: http://www.pessoacomdeficiencia.gov.br/app/ Acesso em: 14 set. 2019.

CTA - Centro Tecnológico de Acessibilidade. Acessibilidade e tecnologia assistiva: pensando a inclusão sociodigital de PNEs. 27/11/2018; Bento Gonçalvez: Disponível em: http://cta.ifrs.ed.br. Acesso em: 14 set. 2019.

GOMES, Danila; QUARESMA, Manuela. Introdução ao design inclusivo. - Curitiba: Appris, 2018.

IIDA, Itiro. Ergonomia: projeto e produto. $2^{\underline{a}}$ edição rev. e ampliada. - São Paulo: Edgard Blücher, 2005.

Minha Vida. Esclerose Múltipla: sintomas, tratamentos e causas. 02/10/2018; São Paulo: Disponível em: http://www. minhavida.com.br. Acesso em: 14 set. 2019.

MORAES, Anamaria de; MONT'ALVÃO, Cláudia. Ergonomia: conceitos e aplicações. $2^{\underline{a}}$ edição ampliada - Rio de Janeiro: 2 AB, 2000.

SANTOS, Neri dos.; FIALHO, Francisco. Manual de Análise Ergônomica do Trabalho. Curitiba: Genesis, 1995. 